\title{
O DNA: a molécula da vida
}

\section{DNA: the molecule of life}

João José da Silva Carrilho ${ }^{1}$

jjdscarrilho@gmail.com.br

\section{Resumo}

Este artigo pretende mostrar que podemos estabelecer relações interdisciplinares, através do conhecimento mais detalhado da molécula do DNA. Para tanto, é necessário que o professor saiba como detectá-lo e, a partir de sua detecção, utilizálo como um objeto estruturante na construção do conhecimento. Com isso, o aluno deve perceber que, para entender a molécula do DNA, é necessário associar o conhecimento da Lei de Coulomb na evolução das espécies, além da necessidade de outros aspectos, como a teoria do caos e a entropia presente no processo, para uma melhor compreensão do tema. Depois disso, faz-se a análise e comparação, permeadas por uma base teórica, que visa a consubstanciar o que foi discutido. Este artigo é finalizado com algumas atividades pedagógicas, que podem ser aplicadas e discutidas para melhor apropriar-se do tema e alcançar alguns objetivos que fazem parte da matriz curricular, proposta pelos Parâmetros Curriculares Nacionais (PCNs) dos ensinos fundamental e médio.

Palavras-chave: DNA, lei de Coulomb, Teoria do caos, Entropia

\section{Abstract}

This article aims to show that we can establish interdisciplinary relations through more detailed knowledge of the DNA molecule. Therefore, it is necessary that the teacher knows how to detect it and, from its detection, uses it as a structural object in the construction of knowledge. Thus, the student shall realize that to understand the DNA molecule, it is necessary to associate the knowledge of Coulomb's law in the evolution of species and also observe the need of other aspects such as chaos theory and entropy in this process for a better understanding of the subject. After that, we have an analysis and comparison, permeated by a theoretical foundation that aims to substantiate what was discussed. This article ends with some pedagogical activities that can be applied and discussed to better take ownership of the issue and reach some goals which are part of the curriculum proposed by the National Curriculum Parameters (PCNs) of primary and secondary education.

Keywords: DNA, Coulomb's law, Chaos theory, Entropy

1 Bacharel em Ciências Naturais com habilitação em física e matemática, Especialista em Ensino de Astronomia e Mestrando em Astronomia pela Universidade Estadual de Feira de Santana.

Revista Educação Online, n. 18, jan-mai 2015, p. 


\section{Introdução}

A natureza tem uma tendência natural, na qual parece fundamental manter, espontaneamente, certo grau de desordem, o que podemos notar em fenômenos simples ou em unidades complexas como a molécula do DNA².

Essa complexidade nos faz indagar: $O$ que podemos explorar sobre essa molécula?

Sabe-se que todo conhecimento é resposta a uma pergunta. Como afirma Bachelard (1996), "o espírito científico proíbe que tenhamos uma opinião sobre questões que não sabemos formular com clareza. Em primeiro lugar, é preciso saber formular problemas" (BACHELARD, 1996, p. 18).

Então, podemos começar com algumas perguntas, o que permitirá o início de uma discussão sobre essa molécula fundamental para a vida, da forma que a conhecemos. Será que podemos sobreviver em um mundo que não tenha uma ordem ou uma tendência de redução de desordem? O que se faz necessário, para que ocorra uma organização?

Podemos dizer que é necessária alguma ação que restabeleça um mínimo de ordem. Se não houver nenhuma ação nesse sentido, a tendência é que a desorganização prevaleça.

A necessidade da existência da ordem/desordem está relacionada com a segunda lei da termodinâmica, que traduz uma característica fundamental da natureza, a qual denominamos entropia. Ela é a função irmã e espelho da energia. No sentido que a entropia se maximiza, a energia atinge seu nível mínimo, que é a tendência de tudo no Universo. Por sua vez, podemos relacioná-la com a quantidade de informação necessária para caracterizar um sistema, o quão o mesmo está relaxado. Dessa forma, quanto maior a entropia, menos estruturado está e mais informações são necessárias para descrever esse sistema, seja ele inanimado ou animado.

Podemos conceber a manutenção dos processos naturais, assim como a própria vida, como um embate constante contra a entropia. Travamos a cada momento uma luta contra a desorganização. Desde o primeiro instante de nossa existência, logo a partir da fecundação do óvulo pelo espermatozoide, o nosso organismo se torna cada vez mais desenvolvido, ficando mais complexo. Começamos a partir de duas células: o óvulo e o espermatozoide, e chegamos à fase adulta com 
trilhões delas especializadas em determinadas funções. Entretanto, com o passar do tempo, o nosso organismo não consegue mais vencer essa batalha contra a entropia. Cada célula que surge não consegue manter as mesmas características da original. Começamos a sentir os efeitos dessa desordem e do tempo, começamos a envelhecer. Percebemos, então, que a manutenção da vida é uma luta constante pela organização, quando essa cessa, imediatamente o corpo começa a se deteriorar e a perder todas as características que levaram muitos anos para se estabelecerem.

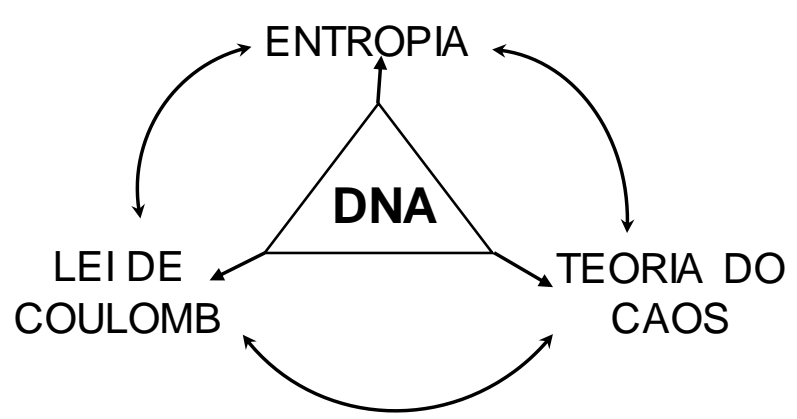

Figura 1

As leis e conceitos aplicados ao micro, nesse caso o DNA, são válidos para o Universo. Como exemplo próximo, sabemos que toda forma de energia tem sua origem no sol, quando esse não puder mais fornecer essa energia, possivelmente daqui a cinco bilhões de anos, não existirá mais vida na Terra. Com certeza, a espécie humana já terá sido extinta muito antes disso, se não procurar outro sistema estelar.

Até mesmo o Universo, como um todo, não resistirá ao embate contra o aumento da entropia. A segunda lei da termodinâmica permite dizer que: considerando o Universo como um sistema isolado, a sua entropia aumenta sempre. Em uma escala inimaginável de tempo de $10^{100}$ anos (1 seguido de 100 zeros!), se ele continuar a sua expansão, que já dura 13,8 bilhões de anos, tudo o que conhecemos estará absolutamente disperso e terminará muito frio e a entropia, finalmente, vencerá.

\section{Forças da natureza}

Sabemos que existem apenas quatro forças, ou interações, fundamentais na natureza. São elas a interação gravitacional, a interação eletromagnética, 
a interação forte e a interação fraca. Cada uma delas está associada a uma teoria física e se deve a uma partícula mediadora. A tabela 1 mostra de maneira simplificada detalhes sobre estas forças (GAROTTI, SD).

\begin{tabular}{|c|l|c|c|}
\hline $\begin{array}{c}\text { Interação } \\
\text { fundamental }\end{array}$ & Intensidade & Teoria & $\begin{array}{c}\text { Partícula } \\
\text { mediadora }\end{array}$ \\
\hline forte & 10 & $\begin{array}{c}\text { cromodinâmica } \\
\text { quântica }\end{array}$ & gluon \\
\hline eletromagnética & $10^{-2}$ & Eletrodinâmica & fóton \\
\hline fraca & $10^{-13}$ & Flavordinâmica & $W^{ \pm}$e Z \\
\hline gravitacional & $10^{-42}$ & Geometrodinâmica & graviton $^{3}$ \\
\hline
\end{tabular}

Tabela 1: Forças, intensidade, teoria e partícula mediadora. Fonte: GAROTTI, SD

Considerando as interações dadas na tabela, podemos usá-las para explicar a necessidade de cada uma delas para a existência de tudo que existe na Natureza. A interação nuclear fraca é responsável pela explicação que possibilita unir os quarks na formação de prótons e nêutrons. A estabilidade nuclear está associada à força forte, é ela que mantém o núcleo unido, evitando que os prótons que os constituem, por possuírem a mesma carga elétrica, simplesmente sofram uma intensa repulsão e destrua o próprio átomo.

A interação gravitacional, que explica como a Terra e a Lua se atraem, como os sistemas de grandes massas interagem para conceber todo o Cosmo, é a força de maior alcance, sendo também a mais fraca de todas. Tendo sido enunciada, em meados do século XVII, pelo físico e matemático inglês, Isaac Newton.

Uma reação química é uma manifestação da força elétrica, é ela que explica a formação dos átomos, e esses, através das ligações eletrostática ou eletromagnética, formam as moléculas; quase tudo em nosso corpo está sob o comando dessa força elétrica. Enquanto lemos esse texto ou ouvimos uma música, seguramos uma caneta, estamos sobre a ação da interação elétrica, que será utilizada para a compreensão da molécula do DNA.

3 Teórico. 
Coube a Charles Augustin Coulomb (1736-1806), em 1785, investigando indícios de regularidades nas relações entre cargas puntiformes, estabelecer que esses corpos se atraem ou se repelem, devido apenas a três fatores: o produto da quantidade de elétrons ou prótons que cada corpo possui em excesso, indicada pelas cargas elétricas dos corpos, Q1 e Q2; o inverso do quadrado da distância que separa os seus centros, d; e ao meio entre eles (chamado de dielétrico), representado por uma constante inerente a esse meio, a constante eletrostática, $\mathrm{K}$.

Essa força é atrativa, se as cargas tiverem sinais opostos; é repulsiva, se as cargas tiverem o mesmo sinal. Quem primeiro percebeu esse comportamento foi o cientista francês François du Fay (1698-1739).

A força entre duas cargas elétricas (ou dois corpos eletrizados) é diretamente proporcional ao módulo do produto das suas cargas e inversamente proporcional ao quadrado da distância entre elas. A direção desta força mútua está sobre a linha reta que liga as cargas, e o seu sentido depende das suas naturezas. (LIPINSKI, 2008, p.9)

Tendo em vista essas informações, podemos escrever que o módulo do vetor força elétrica, que atua entre duas cargas elétricas pontuais, pode ser escrito como:

$|\vec{F}|=\frac{1}{4 \pi \cdot k \cdot \varepsilon_{o}} \frac{Q_{1} \cdot Q_{2}}{d^{2}}$, que é a expressão matemática da Lei de Coulomb.

Sendo k uma constante de proporcionalidade, que mostra a dependência da força elétrica com o meio, através de outra constante, ${ }^{\varepsilon_{0}}$ denominada permissividade do vácuo.

O valor de ${ }^{\mathcal{E}}{ }_{O}$ no ar é muito próximo do valor da permissividade do vácuo. Assim, podemos fazer uma aproximação o que nos permite escrever com as unidades do sistema internacional como:

$$
\varepsilon_{0}=8,854 \times 10^{-12} N^{-1} \cdot m^{-2} C^{2} .
$$

A constante $k$, chamada constante dielétrica, assume valores que depende das características do meio isolante que circunda as cargas elétricas, tendo, portanto, valores que dependem do meio, conforme mostramos na tabela 2. 


\begin{tabular}{|c|c|}
\hline MEIO & $\boldsymbol{\varepsilon}_{\mathrm{r}}$ \\
\hline vácuo & 1,0 \\
ar & 1,0 \\
óleo & 4,6 \\
parafina & 6,5 \\
glicerina & 43 \\
água & 81 \\
álcool & 25 \\
papel & 3,5 \\
vidro & 4,5 \\
mica & 5,4 \\
\hline
\end{tabular}

Tabela 2: Meios e correspondente permissividade

Do exposto na tabela acima e com base nela, podemos inferir que a força elétrica tem intensidade máxima no ar e no vácuo, e valor mínimo na água, ou seja, ela depende do meio material no qual as cargas elétricas estão imersas. Desse comportamento, é fundamental entendermos uma importante função das enzimas que atuam para enfraquecer as pontes de hidrogênio nas ligações elétricas entre as bases nitrogenadas, presentes no DNA.

\section{A Teoria do Caos}

Esse tipo de imprevisibilidade nunca foi segredo, mas a coisa ganhou ares de estudo científico sério, no início da década de 1960, com o meteorologista americano Edward Lorenz, que descobriu que fenômenos aparentemente simples têm um comportamento tão caótico quanto à vida. Ele chegou a essa conclusão, ao testar um programa de computador que simulava o movimento de massas de ar (TANABE, 2011, p.5).

Um dia, Lorenz teclou um dos números que alimentava os cálculos da máquina com algumas casas decimais a menos, esperando que o resultado mudasse pouco, mas a alteração insignificante transformou completamente o padrão das massas de ar. A existência de sistemas dinâmicos, intrinsecamente determinísticos, com comportamento caótico, isto é, em que a transição do sistema de um estado para outro só pode ser descrita em termos probabilísticos, tal como acontece com 
processos verdadeiramente randômicos, já havia sido assinalada por Henri Poincaré, no início deste século. Poincaré, entretanto, deixou o assunto de lado, considerando-o apenas uma curiosidade matemática. $O$ que motivou o grande interesse por tais sistemas, a partir dos anos 1980, foi à descoberta de que, ao invés de se constituir numa raridade matemática, a maioria dos sistemas dinâmicos apresenta a propriedade acima descrita e, mais ainda, que esse tipo de comportamento é comum à maioria dos fenômenos naturais e sociais, e não apenas uma propriedade de leis matemáticas abstratas. Além disso, mesmo modelos matemáticos muito simples, representativos de sistemas físicos ou socioeconômicos, podem apresentar, sob determinadas circunstâncias, comportamentos totalmente aleatórios, mostrando-se hipersensíveis a variações nas condições iniciais. Tais descobertas estão determinando o estabelecimento de um novo paradigma para todas as ciências, natural ou social, constituindo-se numa verdadeira revolução no pensamento científico. A ciência clássica, fruto e avalista de uma cultura e uma época nas quais a humanidade, ao inventar a máquina e erigir sistemas sociais democráticos, parecia prestes a submeter inteiramente a natureza ao seu controle, buscou meios de descrevê-la de forma objetiva, usando, como paradigma, o funcionamento da máquina. Dessa forma, ela sempre imaginou que tais sistemas evoluíssem de forma contínua e perfeitamente antecipável em qualquer ponto do futuro, isto é, sempre se supôs que sistemas determinísticos só pudessem apresentar trajetórias temporais perfeitamente previsíveis (TANABE, 2011, p.5).

Dentro desse raciocínio, podemos exemplificar o movimento de uma bola chutada do alto de um prédio, depois sendo levada por uma corrente de ar e depois caindo em um rio. Será possível determinar o local exato onde a bola está, após um intervalo de tempo de duas horas? Podemos notar aí um movimento caótico, ou seja, um movimento de difícil previsão; mas, se forem dadas as condições inicias, módulo, direção e sentido da força aplicada no chute, módulo, direção e sentido do vento, assim como os dados da correnteza, podemos, sim, localizar com boa precisão o local onde a bola se encontra. Temos de admitir uma pequena taxa de erro na nossa resposta, mas, com certeza, será muito pequena.

De maneira análoga, no interior dos cromossomos, durante a duplicação do DNA e sua replicação, por ação teremos um caos também estabelecido, como descreveremos mais adiante, mas a lei de Coulomb, descrita anteriormente, 
consegue manter uma pequena ordem nesse caos, e isso é de suma importância como veremos a seguir.

Em qualquer dos sistemas descritos, podemos garantir também que qualquer pequena diferença na disposição dos componentes do sistema inicial, trará impacto não negligenciável sobre o resultado final.

\section{0 ácido desoxirribonucleico (o DNA)}

Podemos dizer que o DNA, ou ADN em português, é a molécula da vida, em tudo que tem vida na Terra, ela está presente, mesmo depois da morte. Sua estrutura foi descoberta conjuntamente pelo norte-americano James Watson e pelo britânico Francis Crick em 1953, que nove anos, depois foram agraciados com o Prêmio Nobel de Medicina (AMABIS, 2001 p.152).

O ácido desoxirribonucleico (DNA) é um composto orgânico, cujas moléculas contêm as instruções genéticas que coordenam o desenvolvimento e funcionamento de todos os seres vivos e de alguns vírus, tendo o papel de armazenar as informações necessárias para a construção das proteínas e RNA ${ }^{4}$ (AMABIS, 2001, p.154).

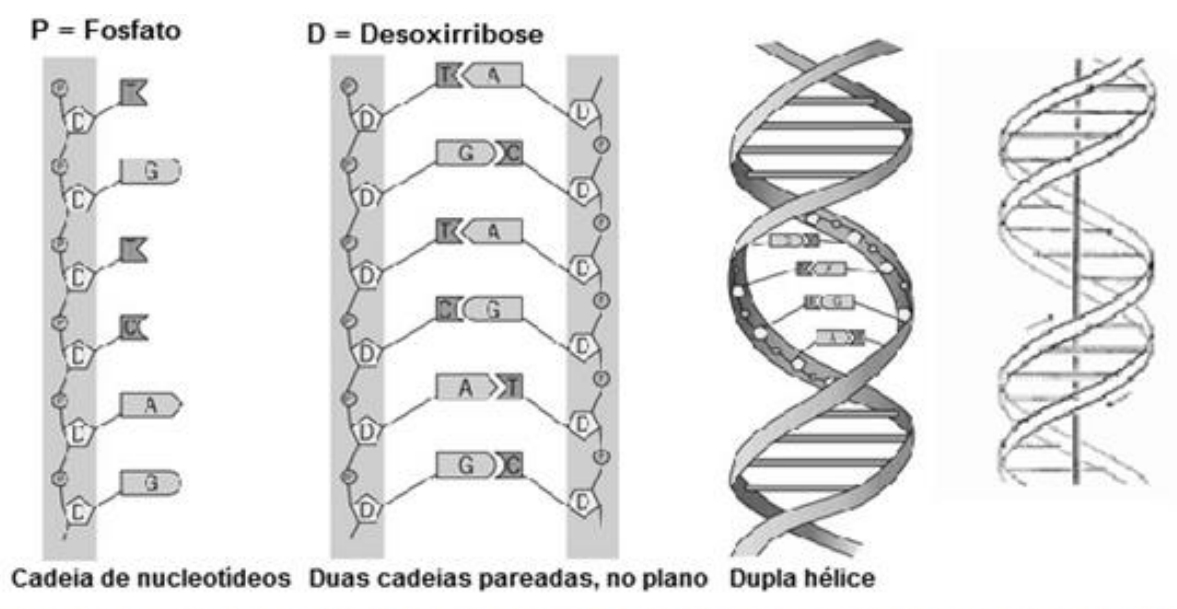

Figura 2: Estrutura da molécula do DNA, a dupla hélice e o desenho de Watson e Crick (Amabis, p.152)

O DNA pode ser encontrado no núcleo das células de um organismo, no interior dos cromossomos, menos nas hemácias (glóbulos vermelhos), que não possuem núcleo, ou também pode ser encontrado na mitocôndria, onde o material genético mitocondrial é herdado exclusivamente da parte materna. É esse DNA

\footnotetext{
${ }^{4}$ Sigla para ácido ribonucleico, que é responsável pela síntese de proteína da célula.
} 
mitocondrial que permite obter informação sobre um ser, mesmo que estejam em estado avançado de degradação. No DNA, os segmentos que contêm a informação genética são denominados genes, já o resto da sequência tem importância estrutural ou está envolvido na regulação do uso da informação genética.

Assim, com exceção de gêmeos univitelinos, o DNA de cada indivíduo é exclusivo, cada ser humano possui duas partes de cada gene, uma que recebe da mãe, outra que recebe do pai. Mesmo sendo a maioria dos genes iguais entre as pessoas, algumas sequências do DNA variam de pessoa para pessoa. É esse o motivo que permite saber a paternidade de uma criança, faz-se o teste de DNA, que vai confirmar sua origem genética.

Os exames para a identificação humana por DNA podem ser utilizados para rapidamente estabelecer vínculo genético, eliminar falsas suspeitas ou associar criminosos a cenas de crime e essas entre si, acarretando significativa economia de tempo e dinheiro à Justiça. Contudo, ao contrário do que muitos imaginam, as técnicas envolvidas nas tipagens genéticas não são isentas de erros (PARADELA et al, 2006; MELGAÇO, 1998).

Nesses exames, a validade dos resultados depende de vários fatores, dentre os quais se destaca o cálculo das frequências populacionais dos marcadores utilizados, uma vez que pode haver variações entre grupos populacionais (EVETT; WEIR, 1998; WEIR, 1996). Para investigações de paternidade, por exemplo, o índice mínimo desejado, para que se possa afirmar esse grau de parentesco entre um indivíduo e seu suposto pai, é de 99,99\%. De acordo com o número e o tipo de marcadores genéticos empregados, as variações populacionais podem interferir no índice de paternidade (MELENDEZ, 2001).

A figura 3 mostra as pontes de hidrogênio que se estabelecem entre as moléculas de timina $(\mathbf{T})$ e adenina $(\mathbf{A})$ e entre as moléculas de citosina $(\mathbf{C})$ e de guanina $(\mathbf{G})$. Observe que existem duas pontes de hidrogênio entre $T$ e $A$, e três entre C e G. 

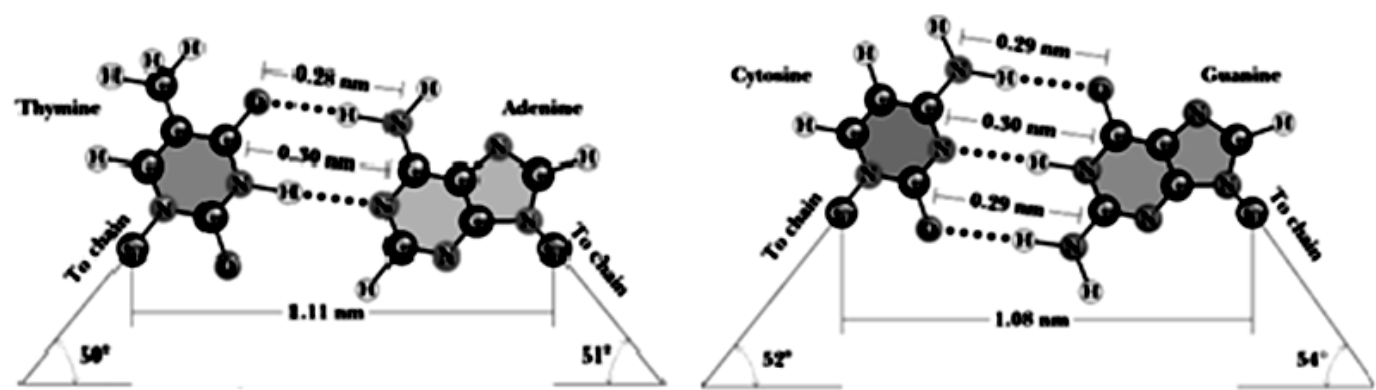

Figura 3: Estrutura da molécula do DNA, com ligações e âqulos. Fonte: http: //www.esec-odivelas.rcts.pt/BioGeo/ficha trab2.htm

Durante o processo de duplicação do DNA, que ocorre antes da divisão celular, os dois "corrimãos" da dupla hélice se separam com a ajuda de enzimas, que também agem por forças eletrostáticas, deixando carregadas as regiões das bases orgânicas expostas. Cada filamento simples se transforma, então, numa matriz para a formação do seu filamento complementar.

Entretanto, existem muitos nucleotídeos dos quatro tipos vagando pelo fluido celular. Mas, para um dado nucleotídeo - G, por exemplo - existe apenas um tipo, dentre as quatro bases, que irá experimentar uma grande atração eletrostática se estiver suficientemente próximo - será a base C. As cargas das outras bases (A e T) não podem se aproximar suficientemente das cargas da base $G$, de modo a se unirem a ela pelas pontes de hidrogênio - lembre-se de que a força eletrostática depende do meio e diminui drasticamente com o aumento da distância.

A taxa de erro durante a replicação do DNA, digamos uma base T incorporada a uma base $\mathrm{G}$ em uma nova cadeia, é da ordem de 1 em $10^{4}$ - e é mantida ainda mais baixa ( 1 em $10^{8}$ a $1^{9}$ ) pela ação de mecanismos enzimáticos de revisão e reparação. Tal erro constitui uma mutação espontânea e deve introduzir uma mudança em alguma característica do organismo. É importante para a sobrevivência do organismo, que essa taxa de erro seja baixa, mas se ela fosse igual à zero, a evolução da espécie, que pode ocorrer apenas através das mutações, seria interrompida.

O ponto a se destacar é que, no interior das células, onde o movimento das células é caótico e desordenado, as forças de origem eletrostática trazem um pouco de ordem ao caos, de modo que a taxa de erros é baixa, suficiente apenas para garantir a evolução das espécies. 


\section{Considerações finais}

Há nos PCNs para o ensino fundamental e médio, a indicação de que devemos abordar conceitos multidisciplinares e que possam enquadrar-se como o tema do artigo, visto que esses fazem parte da matriz curricular.

De acordo com o que foi abordado, partindo do ensino da molécula do DNA, podemos discutir conteúdos relacionados à biologia, a física e a matemática e, assim, constituir atividades pedagógicas, levando problemas para os futuros educadores dos ensinos fundamental e médio.

Acreditamos, como educadores, que a nossa preocupação é motivar mais os nossos estudantes. Sabemos que a literatura é pobre, nos livros didáticos, quanto ao tema em discussão, especialmente no que diz respeito a estabelecer essas relações; por isso, propomos as atividades, atendendo o que prescreve os novos Parâmetros Curriculares Nacionais, especificamente para a área de ciências.

Esperamos que as evidências deixadas com a discussão realizada neste artigo, no mínimo, proporcionem reflexões sobre o que não somos os primeiros a evidenciar.

\section{Atividades pedagógicas propostas}

I - Nesta atividade, podemos entender, por analogia, como funciona a eletroforese do DNA.

Material

- Um pequeno copo com um pouco de álcool;

- Quatro tiras de papel guardanapo com 1,0 cm x 5,0 cm;

- Quatro palitos;

- Quatro canetas diferentes;

- Um grampeador.

1 - Vamos fazer um traço grosso a 2,0 cm de uma das extremidades da tira de papel;

2 - Agora, usando o grampeador, vamos prender a outra extremidade da tira no palito, que servirá para apoiar nas bordas do copo;

3 - Após prender a tira de papel no palito, vamos mergulhar apenas uma pequena parte da extremidade que tem o traço que marcamos; 
4 - Após um minuto, retire a tira do álcool, coloque sobre um pedaço de guardanapo e observe como a tinta da caneta foi distribuída.

5 - Peça a um colega que numere e marque um traço, em outras quatro tiras no papel guardanapo, da mesma forma que você fez e, após um minuto, passe para você.

6 - Identifique de que caneta (mãe) é cada traço feito.

7 - O meio em que a tinta é dissolvida é a tira de papel e o espalhamento da tinta de uma mesma caneta são idênticos? A que podemos relacionar ao artigo?

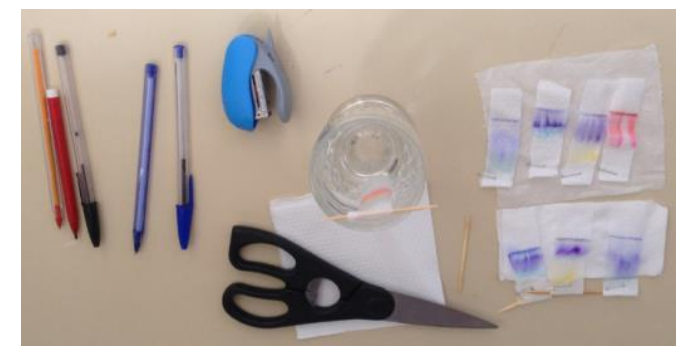

II - Esta é outra atividade, similar a anterior. Para realiza-la, precisamos de:

- Três pequenos copos com uma gelatina transparente e pouco consistente (rala);

- Três porções: uma com três grãos de arroz, quatro grãos de feijão e dois grãos de milho, outra com quatro grãos de arroz, dois grãos de feijão e três grãos de milho e finalmente uma com uma dois grãos de arroz, três grãos de feijão e três grãos de milho.

1 - Vamos misturar os grãos de cada porção;

2 - Agora vamos deixar cair de uma mesma altura e dentro da gelatina, de modo que os grãos penetrem nela e caiam todos dentro do copo.

3 - Após realizar a etapa anterior, devemos comparar os padrões nos copos. São iguais?

4 - Se repetirmos a experiência, podemos encontrar algum padrão? Justifique e explique com base no conteúdo do artigo.

\section{Referências bibliográficas}

GAROTTI, H.; As quatro forças fundamentais. Disponível em <http://www.if.ufrgs.br/tex/fis01043/20032/Humberto/index.html>. Acesso em 12/11/ 2014. 
AMABIS, José Mariano; MARTHO, Gilberto Rodrigues. Fundamentos da biologia moderna. 2aed. São Paulo: Moderna, 2001.

MELGAÇO, M.; FIGUEIREDO, A. S.; PARADELA, R.; Investigação de vínculo genético por análise do DNA: os dados sempre oferecem suporte às conclusões? Disponível em < http://www.amb.com.br/portal/docs/artigos/dna1.pdf>. Acesso em 07/03/ 2015.

TANABE, M.; Teoria do caos e aprendizagem: uma primeira especulação. Disponível em

$<$ http://www.angrad.org.br/_resources/files/_modules/producao/producao_531_20121 2051834228e9c.pdf >. Acesso em 02/03/2015. 